\title{
Socio-demographic Factors as Predictors of Adolescents Resilience: Locale-wise Study
}

\author{
Dahun Massar*, Prema B. Patil and Lata Pujar \\ Department of Human Development and Family Studies, College of Community Science, \\ University of Agricultural Sciences, Dharwad - 580005, Karnataka, India \\ *Corresponding author
}

\section{A B S T R A C T}

\begin{tabular}{l} 
K e y w o r d s \\
$\begin{array}{l}\text { Adolescents, } \\
\text { Resilience, Socio- } \\
\text { demographics } \\
\text { factors (Individual, } \\
\text { Parental \& familial } \\
\text { factors), Locale- } \\
\text { wise }\end{array}$ \\
$\begin{array}{l}\text { Article Info } \\
\text { Accepted: } \\
\text { 04 August } 2020 \\
\text { Available Online: } \\
\text { 10 September } 2020\end{array}$ \\
\hline
\end{tabular}

Introduction

In the course of growing up, adolescents are likely to experience difficult circumstances and stressful life events. For adolescents, these difficult circumstances can include everyday challenges such as arguments with friends, sporting losses or disappointments with test results. More serious problems commonly encountered are family breakdown, illnesses or deaths of family members or friends, or being the victim of bullying. The ability to recover or 'bounce back' from setbacks, adapt to difficult circumstances that cannot be changed, and learn and grow from such experiences is termed 'resilience' (Masten, 2014; Rutter, 2006). Resilience is an important skill for navigating life's ups and downs, which would be beneficial to enhance in young people, as there are concerns that there is a dearth of literature on adolescents' resilience and well being in the particular region.

In general, research suggests that a person's resilience is determined by a variety of 
factors, including individual, biological and psychological characteristics, relationships with family and peers, and environmental influences such as those in the school and broader community (VicHealth, 2015b). Throughout their lives, children and adolescents might have different vulnerabilities and protective systems affecting their resilience. For example, adolescents may be particularly vulnerable to stresses relating to family, friends and schools (Wright and Masten, 2005). Significant changes in social environments in late adolescence and the transition to adulthoodincluding employment, tertiary education and/or leaving the family home - may also affect resilience (Burt and Paysnick, 2012). Resilience can change as individuals interact with and respond to people in their lives and their environments. This creates opportunities to promote resilience in young people in different settings (Masten, 2009). So, in this study the objective was to assess levels of self reported resilience at age 13-17 years and to examine whether resilience differs in two settings (i.e., urban and rural settings). The insights in this study may help us to know the determinant factors that might be associated with adolescents' resilience.

\section{Materials and Methods}

\section{Population of the study}

The target population of the study was adolescents studying in $7^{\text {th }}, 8^{\text {th }}$ and $9^{\text {th }}$ standards from government and private schools. The criteria for selection of the participants were adolescent boys and girls who belonged to intact family and in the age group of 13 to 17 years. The urban adolescents were drawn randomly from urban schools (two private and two government schools) and for rural adolescents were drawn from rural schools (two private and two government schools) in four villages of West
Jaintia hills district, Meghalaya. A total of eight schools were selected randomly situated in urban and rural areas. From each school, adolescents studying in $7^{\text {th }}, 8^{\text {th }}$ and $9^{\text {th }}$ standards were sample for the study. In all the selected schools, the minimum strength of students in each class was 35 students. Nearly fifty percent of the population was drawn randomly. Out of minimum strength in each class, around 15 to 20 adolescents belonging to intact family were drawn randomly; this makes a total of 45 adolescents drawn from three standards in each school. From all the eight schools, a total of 360 adolescents participated in the study. Further, parents (i.e., either a mother or father) of those adolescents who participated in the study were drawn purposively on the basis of being a literate parent belonging to intact family. Parent questionnaires were distributed to all the adolescents. Out of 360 sets of questionnaires, a total of 262 participants returned filled questionnaire, out of which 151 are the urban parents and 111 are the rural parents. Thus, the final sample for the study constituted of 262 parent-adolescents dyad.

\section{Measures}

The resiliency scale for children and adolescents (RSCA) developed by PrinceEmbury (2006) was used for assessing resiliency of children and adolescents aged 8 to 18 years. The resiliency scale comes in brief formats, self- report scales designed to identify areas of perceived strength and of vulnerability in a way that translates these qualities into working that is easily understood by youths and their caregivers. The scales are administered to group of adolescents. It consists of 64 items. Response options are ordered on a 5-point Likert-type scale: 0 (never), 1 (rarely), 2 (sometimes), 3 (often), and 4 (almost always). Higher score indicates greater resiliency. The scale contains subscales that are theoretically 
grounded. The subscales are the Sense of Mastery Scale (MAS), Sense of relatedness scale (REL) and Emotional reactivity scale (REA). A sense of mastery in children and youth provides the opportunity for them to interact with and enjoy cause and effect relationship in the environment. It has a total of 20 items. The total raw score for MAS subscale ranges from 0-80. A Sense of relatedness scale (REL) Cornell and Wellborn (1991) claimed that "relatedness" is one of three basic human needs. It can be defined as "feeling securely connected to individuals in a social context". It has a total of 24 items. The total raw score for REL subscale ranges from 0 to 96 . An emotional reactivity scale (REA) can be viewed as pre-existing vulnerability, arousal, or threshold of tolerance to stimulation prior to the occurrence of adverse events or circumstances. It has a total of 20 items.

The Guttman split-half reliability for each scale was calculated using pre-tested data $(\mathrm{N}=40)$ and the reliability indexes of sense of mastery $(\alpha=0.88)$, sense of relatedness $(\alpha=0.90)$ and sense of emotional reactivity ( $\alpha$ $=0.90$ ) was found.

\section{Socio-economic status}

Socio- demographic factors was measured using scale developed by Aggarwal et.al. (2005). It consists of 23 statements which assess gender, ordinal position, parents' education, occupation, location, type of family, number of children, possessions of agricultural land, domestic animals and socioeconomic status of the family. The reliability index of this scale was 0.89 .

\section{Statistical Analysis}

Bivariate correlation was employed to know the strength of association or relationships between selected socio-demographic factors with adolescents' resiliency. Hierarchical regression analysis was used to determine the predictive variables of adolescents' resilient behavior outcomes. Three blocks of sociodemographic factors (i.e., individual factors, parental factors and familial factors) were regressed onto each subscales of resiliency scale. Each block contained the sociodemographic variables from the previous block and also included new sociodemographic variables in order to determine how additional factors influence resiliency outcomes. The first block regressed individual factors (age, gender and ordinal position) onto the resilience subscales respectively. The second block regressed individual factors plus parental factors (i.e., parents' education and occupation). The third block regressed the individual factors, parental factors and familial factors to analyze the level of contributions onto adolescents' resiliency.

\section{Results and Discussion}

\section{Locale wise comparison of adolescents' resiliency}

Table 1 shows the comparison of urban and rural adolescents' resiliency. The mean of urban adolescents' sense of mastery and sense of relatedness was significantly higher than rural adolescents while the mean of rural adolescents' sense of emotional reactivity was significantly higher than urban adolescents. The results suggested that adolescents growing up in rural locality may face an array of adverse experiences that place them at heightened risk for emotional problems that hamper their resilience. Conger and Conger (2002) argued on social and emotional impacts of living in disadvantaged areas for adolescents tend to fall in the areas of lowered self-esteem, impaired interpersonal skills, increased aggression, greater antisocial behavior, increased stress and anxiety, higher rates of depression and other general behavior 
problems. Similarly, studies (Evans and English, 2002) have shown that rural youth showed difficulty with self-regulation. In the school setting, low-income rural adolescents showed a lower sense of belonging to their school than their more advantaged peers as well as greater exposure to stressful life events.

\section{Relationships between selected factors and adolescents' resiliency}

Table 2 shows the relationships between selected factors and adolescents resiliency. Among individual factors, age was significantly and positively correlated with urban $(\mathrm{r}=0.30)$ and rural $(\mathrm{r}=0.31)$ adolescents' sense of emotional reactivity. Rural adolescents' gender was positively correlated $(r=0.28)$ with sense of relatedness and ordinal position was negatively correlated with sense of mastery and relatedness. With respect to parental factors, parent's education and occupation showed a significant positive correlation with urban and rural adolescents' sense of mastery, sense of relatedness and positive correlation with sense of emotional reactivity.

Regarding familial factors, type of family $(\mathrm{r}=0.17)$ showed a positive correlation with urban adolescents' sense of relatedness and a negative correlation $(\mathrm{r}=-0.21)$ with rural adolescents' sense of emotional reactivity. Number of children showed a negative correlation with urban and rural adolescents' sense of mastery $(r=-0.42)$ sense of relatedness $(\mathrm{r}=-0.30)$ and positively correlated with urban and rural adolescents' sense of emotional reactivity $(\mathrm{r}=0.35)$. Similarly, socio-economic status showed a positive significant relationships with urban and rural adolescents' sense of mastery, sense of relatedness and negative relationships with sense of emotional reactivity.

\section{Predictors of adolescents' resiliency}

Analysis of predictors (Table 3) of urban adolescents' resiliency shows that among individual factors in model 1, only age revealed a significant predictor of sense of emotional reactivity $(\beta=0.32, p<.01)$. When parenting factors added in model 2, child's age remained a significant predictor of sense of emotional reactivity $(\beta=0.30, p<.01)$ and gender emerged a significant predictor of sense of emotional reactivity $(\beta=-0.19$, $\mathrm{p}<.01)$. Regarding parental factors, mother's education $(\beta=0.16, \mathrm{p}<.05)$ and occupation $(\beta=0.17, \quad p<.05)$ appeared as significant contributors towards sense of mastery. Similarly, mother's occupation $\quad(\beta=0.17$, $\mathrm{p}<.05)$ emerged as significant predictor of sense of relatedness $(\beta=0.26, p<.01)$ and sense of emotional reactivity $(\beta=0.15, p<.05)$. When familial factors added in model 3 , child's age remained as significant contributor of sense of emotional reactivity $(\beta=0.30$, $\mathrm{p}<.01)$ while gender remained significant predictors of sense of emotional reactivity $(\beta=-0.16, p<.01)$. Among parental factors, father's education came out as significant predictor of sense of relatedness $(\beta=0.22$, $p<.05)$ and sense of mastery $(\beta=0.20, p<.05)$. In addition familial factors i.e., socioeconomic status emerged as significant predictor of sense of mastery $(\beta=0.58, p<.01)$, sense of relatedness $(\beta=0.62, p<.01)$ and sense of emotional reactivity $(\beta=-0.49$, $\mathrm{p}<.01$ ). The final model ( $\mathrm{R}$ square) explained $50.1 \%$ of the variance in sense of mastery, $48.3 \%$ in sense of relatedness and $53.7 \%$ in sense of emotional reactivity.

Table 4 shows the predictors of rural adolescents' resiliency. In model 1, only age revealed a significant predictor of sense of emotional reactivity $(\beta=0.33, p<.01)$, gender also emerged for sense of sense of mastery $(\beta=0.18, p<.05)$, sense of relatedness $(\beta=0.29$, $\mathrm{p}<.01)$ and sense of emotional reactivity 
$(\beta=0.20, \quad p<.05)$ and eventually ordinal position for sense of mastery $(\beta=-0.23$, $\mathrm{p}<.05)$, sense of relatedness $(\beta=0.22, \mathrm{p}<.05)$. When parental factors added in model 2 , child's age remained as significant predictor of sense of emotional reactivity $(\beta=0.24$, $\mathrm{p}<.01)$ and also gender for sense of sense of mastery $(\beta=0.17, p<.05)$, sense of relatedness $(\beta=0.32, \quad p<.01)$ and sense of emotional reactivity $(\beta=0.21, \quad p<.01)$ while ordinal position for sense of mastery $(\beta=-0.16, p<.05)$ and sense of relatedness $(\beta=-0.16, p<.05)$. Among parental factors, only father's and mother's occupation appeared as significant predictors of sense of relatedness $(\beta=0.20$, $\beta=0.21 \quad p<.05$ respectively) and sense of emotional reactivity $(\beta=-0.19, p<.05)$. When familial factors included in model 3 , child's age remained significantly for sense of emotional reactivity $(\beta=0.27, p<.01)$ while gender for sense of relatedness $(\beta=0.29$, $\mathrm{p}<.01)$ and sense of emotional reactivity $(\beta=0.18, p<.05)$. Likewise, ordinal position still existed as significant variable of sense of mastery $(\beta=-0.18, p<.05)$, sense of relatedness $(\beta=-0.17, \quad p<.05)$. Mother's occupation reappeared as significant predictor of sense of mastery $(\beta=0.23, \quad p<.05)$ and sense of relatedness $(\beta=0.26, \quad p<.01)$. In addition familial factors i.e., socio-economic status emerged as significant predictor of sense of emotional reactivity $(\beta=-0.25, \mathrm{p}<.05)$. The final model (R square) explained $42.7 \%$ of the variance in sense of mastery, $46.5 \%$ in sense of relatedness and $58.0 \%$ in sense of emotional reactivity.

Table.1 Locale-wise comparison of adolescent's resiliency

\begin{tabular}{|c|c|c|c|c|c|}
\hline \multirow{2}{*}{ Resiliency } & \multicolumn{2}{|c|}{ Urban $(\mathbf{n = 1 5 1})$} & \multicolumn{2}{c|}{ Rural (n=111) } & \multirow{2}{*}{ t } \\
\cline { 2 - 6 } & Mean & SD & Mean & SD & \\
\hline Sense of mastery & 53.51 & 6.99 & 50.42 & 8.02 & $3.23^{* *}$ \\
\hline Sense of relatedness & 55.58 & 5.73 & 53.86 & 6.44 & $2.27 *$ \\
\hline $\begin{array}{c}\text { Sense of emotional } \\
\text { reactivity }\end{array}$ & 49.52 & 6.38 & 51.00 & 6.99 & 1.78 \\
\hline
\end{tabular}

*Significant at 0.05 level, **Significant at 0.01 level

Table.2 Correlations coefficients between socio-demographic factors and adolescent's resiliency

\begin{tabular}{|c|c|c|c|c|c|c|}
\hline \multirow{2}{*}{$\begin{array}{l}\text { Socio-demographic } \\
\text { factors }\end{array}$} & \multicolumn{3}{|c|}{ Urban } & \multicolumn{3}{|c|}{ Rural } \\
\hline & $\begin{array}{l}\text { Sense of } \\
\text { mastery }\end{array}$ & $\begin{array}{l}\text { Sense of } \\
\text { relatedness }\end{array}$ & $\begin{array}{l}\text { Sense of } \\
\text { emotional } \\
\text { reactivity }\end{array}$ & $\begin{array}{l}\text { Sense of } \\
\text { mastery }\end{array}$ & $\begin{array}{l}\text { Sense of } \\
\text { relatedness }\end{array}$ & $\begin{array}{l}\text { Sense of } \\
\text { emotional } \\
\text { reactivity }\end{array}$ \\
\hline Age & -0.00 & 0.14 & $0.30 * *$ & 0.00 & 0.09 & $0.31 * *$ \\
\hline Gender & 0.03 & 0.00 & -0.10 & 0.18 & $0.28 * *$ & -0.17 \\
\hline Ordinal position & -0.02 & -0.00 & -0.02 & $-0.23 *$ & $-0.22 *$ & 0.12 \\
\hline Fathers' education & $0.42 * *$ & $0.30 * *$ & $-0.36 * *$ & $0.40 * *$ & $0.36^{* *}$ & $-0.41 * *$ \\
\hline Mothers' education & $0.40 * *$ & $0.31 * *$ & $-0.37 * *$ & $0.37 * *$ & $0.34 * *$ & $-0.40 * *$ \\
\hline Fathers' occupation & $0.21 * *$ & $0.17 *$ & $-0.17 *$ & $0.40 * *$ & $0.39 * *$ & $-0.41 * *$ \\
\hline Mothers' occupation & $0.33^{* *}$ & $0.26^{* *}$ & $-0.26 * *$ & 0.11 & 0.09 & $-0.19 *$ \\
\hline Type of family & 0.12 & $0.17 *$ & -0.11 & 0.11 & 0.14 & $-0.21 *$ \\
\hline Number of children & $-0.42 * *$ & $-0.30 * *$ & $0.35 * *$ & $-0.40 * *$ & $-0.42 * *$ & $0.39 * *$ \\
\hline Socio economic status & $0.63 * *$ & $0.54 * *$ & $-0.55^{* *}$ & $0.49 * *$ & $0.44 * *$ & $-0.53 * *$ \\
\hline
\end{tabular}

**. Correlation is significant at the 0.01 level (2-tailed).

*. Correlation is significant at the 0.05 level (2-tailed). 
Table.3 Predictors (hierarchical regression model) of urban adolescent's resiliency

\begin{tabular}{|c|c|c|c|c|c|c|c|c|c|}
\hline \multirow{2}{*}{$\begin{array}{l}\text { Socio-demographic } \\
\text { factors }\end{array}$} & \multicolumn{3}{|c|}{ Model 1} & \multicolumn{3}{|c|}{ Model 2} & \multicolumn{3}{|c|}{ Model 3} \\
\hline & MAS & REL & REA & MAS & REL & REA & MAS & REL & REA \\
\hline \multicolumn{10}{|l|}{ Individual factors } \\
\hline Age & -0.00 & 0.14 & $0.32 * *$ & -0.03 & 0.12 & $0.30 * *$ & -0.04 & 0.11 & $0.30 * *$ \\
\hline Gender & 0.02 & 0.02 & -0.13 & 0.09 & 0.07 & $-0.19 * *$ & 0.08 & 0.06 & $-0.16^{* *}$ \\
\hline Ordinal position & -0.01 & 0.00 & 0.05 & -0.05 & 0.02 & 0.02 & 0.05 & -0.02 & 0.04 \\
\hline \multicolumn{10}{|l|}{ Parental factors } \\
\hline Fathers' education & & & & 0.14 & 0.02 & 0.15 & 0.08 & $0.22 *$ & 0.07 \\
\hline Mothers' education & & & & $0.16^{*}$ & 0.12 & 0.15 & 0.01 & 0.07 & 0.02 \\
\hline Fathers' occupation & & & & 0.00 & 0.04 & 0.00 & 0.06 & 0.02 & 0.06 \\
\hline Mothers' occupation & & & & $0.17 *$ & $0.17 *$ & $0.15^{*}$ & 0.06 & 0.00 & 0.01 \\
\hline \multicolumn{10}{|l|}{ Familial factors } \\
\hline Type of family & & & & & & & 0.07 & 0.11 & 0.03 \\
\hline Number of children & & & & & & & -0.06 & 0.04 & 0.03 \\
\hline Socio economic status & & & & & & & $0.58 * *$ & $0.62 * *$ & $-0.49 * *$ \\
\hline F value & 0.06 & 1.08 & $6.38 * *$ & $8.37 * *$ & $5.28 * *$ & $9.50 * *$ & $9.35 * *$ & $7.61 * *$ & $10.57 * *$ \\
\hline $\mathbf{R}$ & 0.036 & 0.147 & 0.340 & 0.612 & 0.524 & 0.636 & 0.700 & 0.663 & 0.722 \\
\hline R Square & 0.001 & 0.022 & 0.115 & 0.374 & 0.274 & 0.404 & 0.491 & 0.439 & 0.521 \\
\hline R square change & 0.001 & 0.022 & 0.115 & 0.373 & 0.253 & 0.289 & 0.116 & 0.165 & 0.117 \\
\hline
\end{tabular}

Note: MAS-Sense of mastery, REL-Sense of relatedness, REA-Sense of emotional reactivity. Figure shown is $\beta$-beta value. $* p<.05 . * * \mathrm{p}<.01 . * * * \mathrm{p}<.001$

Table.4 Predictors (hierarchical regression model) of rural adolescent's resiliency

\begin{tabular}{|c|c|c|c|c|c|c|c|c|c|}
\hline \multirow{2}{*}{$\begin{array}{l}\text { Socio-demographic } \\
\text { factors }\end{array}$} & \multicolumn{3}{|c|}{ Model 1} & \multicolumn{3}{|c|}{ Model 2} & \multicolumn{3}{|c|}{ Model 3} \\
\hline & MAS & REL & REA & MAS & REL & REA & MAS & REL & REA \\
\hline \multicolumn{10}{|l|}{ Individual factors } \\
\hline Age & 0.00 & 0.11 & $0.33 * *$ & 0.08 & 0.02 & $0.24 * *$ & -0.05 & 0.04 & $0.27 * *$ \\
\hline Gender & $0.18 *$ & $0.29 * *$ & $0.20 *$ & $0.17 *$ & $0.32 * *$ & $0.21 * *$ & 0.15 & $0.29 * *$ & $0.18 *$ \\
\hline Ordinal position & $-0.23 *$ & $-0.22 *$ & 0.12 & $-0.16^{*}$ & $-0.16^{*}$ & 0.03 & $-0.18^{*}$ & $-0.17 *$ & 0.04 \\
\hline \multicolumn{10}{|l|}{ Parental factors } \\
\hline Fathers' education & & & & 0.10 & 0.02 & 0.02 & 0.00 & 0.11 & 0.11 \\
\hline Mothers' education & & & & 0.18 & 0.13 & 0.09 & 0.07 & 0.02 & -0.03 \\
\hline Fathers' occupation & & & & 0.19 & $0.20 *$ & $-0.19 *$ & 0.13 & 0.14 & -0.09 \\
\hline Mothers' occupation & & & & 0.17 & $0.21 *$ & 0.09 & $0.23 *$ & $0.26 * *$ & 0.16 \\
\hline \multicolumn{10}{|l|}{ Familial factors } \\
\hline Type of family & & & & & & & 0.05 & 0.09 & 0.13 \\
\hline Number of children & & & & & & & 0.08 & -0.14 & 0.01 \\
\hline Socio economic status & & & & & & & 0.25 & 0.20 & $-0.25^{*}$ \\
\hline F value & $3.46^{*}$ & $6.07 * *$ & $6.76^{* *}$ & $5.45 * *$ & $6.38 * *$ & $8.55 * *$ & $4.40 * *$ & $5.28 * *$ & $8.62 * *$ \\
\hline $\mathbf{R}$ & 0.298 & 0.381 & 0.399 & 0.594 & 0.624 & 0.679 & 0.626 & 0.660 & 0.746 \\
\hline R Square & 0.089 & 0.145 & 0.159 & 0.353 & 0.390 & 0.461 & 0.391 & 0.435 & 0.557 \\
\hline R square change & 0.089 & 0.145 & 0.159 & 0.264 & 0.244 & 0.302 & 0.038 & 0.046 & 0.096 \\
\hline
\end{tabular}

Note: MAS-Sense of mastery, REL-Sense of relatedness, REA-Sense of emotional reactivity. Note. ${ }^{*} p<.05 .{ }^{* *} \mathrm{p}<.01 .{ }^{* * *} \mathrm{p}<.001$ 
The current study investigated the correlates and prospective predictors of adolescent resilience behaviors, a key for determining risk factors influencing resilience of urban and rural adolescents. Findings indicated that age was positively correlated with adolescents' sense of emotional reactivity, reflecting that older adolescents or as age increased adolescents had higher sense of emotional reactivity (REA), this may be the fact that older adolescents are vulnerable to the state of adverse events or circumstances due to emotional disturbance occurred during the period of adolescence. The findings are in line with Frost and McKelvie (2004) which have found that increase in individual resilience factors such as self-esteem which is one of the resilience factors are age dependent among children and adolescents (aged 5 to 17 years). Regression analyses revealed that age factor accounted for significant variance in REA of urban and rural adolescents. Rural adolescents' gender was positively correlated and prospectively predicted change in resilience behaviors. Ordinal position was negatively correlated with sense of mastery and relatedness. However, a model indicated that ordinal position brought a change in the variance for rural adolescents' resiliency. These results suggest that adolescence is a pivotal period for changes in the growth rate of resiliency by gender (Galambos et al., 2006), for instance sense of relatedness was shown to increase at a faster rate for girls than boys or might be due to differences in parental treatments towards boys and girls in terms of parental support, involvement and provision of sense of trust, confidence and comfort (Prince-Embury, 2006) which was observed only among rural adolescents. Regarding ordinal position, it can be stated that older siblings are more salient that younger siblings, this was explained by social learning theory (Bandura, 1978). It was found that parent's education and occupation was positively correlated with urban and rural adolescents' sense of mastery, sense of relatedness and negatively correlated with sense of emotional reactivity. This is in line with Duncan and Magnuson (2003) findings asserting a strong correlation between parental education, occupation levels and children development. Parent level of education has been found to correlate positively with many aspects of child outcomes and attributes such as high IQ and higher achievement (Felner, 2005). Further explained by Felner (2005), that youth from families where neither parent graduated from the high school exhibited significantly poorer socio-emotional and less positive optimism about future orientation. Von Rueden et al., (2006) found that higher parent education had a significant positive impact on physical wellbeing, psychological well-being, moods and emotions. Regarding familial factors, type of family showed a positive correlation with urban adolescents' sense of relatedness and a negative correlation with rural adolescents' sense of emotional reactivity. These findings highlighted the significant effect of family type on the level of adjustments of adolescents in emotional, social values and educational areas and that varies locally (Puskar et al., 2010). The findings also revealed that adolescents from families with less number of children had significantly higher level of sense of mastery, sense of relatedness and below-average sense of emotional reactivity than those adolescents from families with large number of children. These results suggested that adolescents belonging to small families had higher parental support and guidance leading to high sense of trust, comfort, optimism and adaptability towards adversity and challenges than adolescents from large families where there might be a minimum parental investment towards their well being, leading to high sense of vulnerability and emotional problems. Similarly, socio-economic status (SES) showed a positive correlation with 
urban and rural adolescents' sense of mastery, sense of relatedness and negative relationships with sense of emotional reactivity. Pertaining to SES, it can be explained that good socio-economic status is associated with access to material, cultural and educational resources, making it a significant source of social capital, whereas low family affluence limits access to the aforesaid resources and could become a significant source of stress, having negative consequences on children's development (Bornstein and Bradley, 2003).

In conclusion this study has provided a picture of self reported resilience among adolescents. Resilience levels were related to socio-demographic characteristics, such as age, gender, parent's education, occupation and SES. On average, urban adolescents reported higher levels of resilience (sense of mastery and relatedness) than rural adolescents while rural adolescents had higher levels of sense of emotional reactivity. Relative predictive factors accounted significant variance across different settings.

The findings in this chapter raise suggestions for further research. Further analyses using longitudinal data will allow researchers and practitioners to understand how individual, family, peer, school and community factors act together over time to influence resilience. In addition, opportunities to provide school based intervention at individual level for at risks adolescents in different settings will be helping younger generation to optimize resilient behaviors for their own betterment at present and for their future. A better understanding of resilience, along with its causes and effects on life outcomes, will help parents, teachers and others wishing to foster resilience in young people.

\section{Acknowledgment}

The author thanks the co-authors for their contribution in the research study and to all the participants for their cooperation.

Funding: Under the scheme "National Fellowship and Scholarship for Higher Education of ST Students" to pursue M.Phil./Ph.D. Degree.

Conflict of Interest: None

\section{References}

Bandura, A. 1978. Social learning theory of aggression. J. Communication. 28(3): 12-29.

Bornstein, M. H., and Bradley, R. H. 2003. Socioeconomic status, parenting, and child development. Monographs in Parenting Series, US New Jersey: Lawrence Erlbaum Associates, 189207.

Burt, K. B., and Paysnick, A. A. 2012, Resilience in the transition to adulthood. Development and Psychopathology. 24(2):493-505.

Conger, R. D., and Conger, K. J. 2002. Resilience in Midwestern families: Selected findings from the first decade of a prospective, longitudinal study. $J$. Marriage and Family. 64(2): 361-373.

Connell, J. P., and Wellborn, J. G. 1991. Competence, autonomy, and relatedness: A motivational analysis of self-system processes. In M. R. Gunnar and L. A. Sroufe (Eds.), Self processes and development: The Minnesota symposia on child psychology, Hillsdale, NJ: Lawrence Erlbaum, pp. 43-77.

Duncan, G. J., and Magnuson, K. 2003. Off with Hollingshead: Socioeconomic resources, parenting and child development. In M. Bornstein and R. Bradley (Eds.), Socioeconomic status, parenting, and child development. Mahwah, NJ: Lawrence Erlbaum, pp. 
83-106.

Evans, G. W., and English, K. 2002. The environment of poverty: Multiple stressor exposure, psychophysiological stress, and socioemotional adjustment. Child development.73(4): 1238-1248.

Felner, R. D. 2005. Poverty in childhood and adolescents. In S. Goldstein and R. B. Brooks (Eds.), Hand book of resilience in children, New York: Plenum. pp. 125-147.

Frost, J., and McKelvie, S., 2004, Self-esteem and body satisfaction in male and female elementary school, high school, and university students. Sex roles, 51(12): 45-54.

Galambos, N. L., Barker, E. T., and Krahn, H. J. 2006. Depression, self-esteem, and anger in emerging adulthood: sevenyear trajectories. Developmental psychology. 42(2): 350-365.

Masten, A. S. 2009. Ordinary magic: Lessons from research on resilience in human development. Education Canada. 49: 28-32.

Masten, A. S. 2014. Global perspectives on resilience in children and youth. Child Development. 85(1): 6-20.

Prince-Embury, S. 2006. Resiliency scales for adolescents: Profiles of personal strengths. Canadian J. School Psychology. 23(1):41-56.

Puskar, K. R., Marie Bernardo, L., Ren, D., Haley, T. M., Hetager Tark, K., Switala, J., and Siemon, L. 2010. Self-esteem and optimism in rural youth: Gender differences. Contemporary Nurse. 34(2): 190-198.

Rutter, M. 2006. Implications of resilience concepts for scientific understanding. Annals of the New York Academy of Sciences. 1094, 1-12.

VicHealth. 2015b. Epidemiological evidence relating to resilience and young people: A literature review. Melbourne: VicHealth.

Von Rueden, U., Gosch, A., Rajmil, L., Bisegger, C., and Ravens-Sieberer, U. 2006. Socioeconomic determinants of health related quality of life in childhood and adolescence: Results from a European study. J. Epidemiology and Community Health. 60: 130-135.

Wright, M. O. D., and Masten, A. S. 2005. Resilience processes in development. In S. Goldstein, and R. B. Brooks (Eds.), Handbook of resilience in children (1737). Boston, MA: Springer US.

\section{How to cite this article:}

Dahun Massar, Prema B. Patil and Lata Pujar. 2020. Socio-demographic Factors as Predictors of Adolescents Resilience: Locale-wise Study. Int.J.Curr.Microbiol.App.Sci. 9(09): 91-99. doi: https://doi.org/10.20546/ijcmas.2020.909.011 